\title{
Timing and risks of chemoprophylaxis after spinal surgery: a single-center experience with 6869 consecutive patients
}

\author{
Ekamjeet S. Dhillon, BS, ${ }^{1}$ Ryan Khanna, MD, ${ }^{2}$ Michael Cloney, MD, MPH, ${ }^{1}$ Helena Roberts, ${ }^{1}$ \\ George R. Cybulski, MD, MBA, ${ }^{1}$ Tyler R. Koski, MD, ${ }^{1}$ Zachary A. Smith, MD, ${ }^{1}$ and \\ Nader S. Dahdaleh, MD1
}

'Department of Neurological Surgery, Northwestern University Feinberg School of Medicine; and 'Department of Neurosurgery, Rush University Medical Center, Chicago, Illinois

OBJECTIVE Venous thromboembolism (VTE) after spinal surgery is a major cause of morbidity, but chemoprophylactic anticoagulation can prevent it. However, there is variability in the timing and use of chemoprophylactic anticoagulation after spine surgery, particularly given surgeons' concerns for spinal epidural hematomas. The goal of this study was to provide insight into the safety, efficacy, and timing of anticoagulation therapy after spinal surgery.

METHODS The authors retrospectively examined records from 6869 consecutive spinal surgeries performed in their departments at Northwestern University. Data on patient demographics, surgery, hospital course, timing of chemoprophylaxis, and complications, including deep venous thrombosis (DVT), pulmonary embolism (PE), and spinal epidural hematomas requiring evacuation, were collected. Data from the patients who received chemoprophylaxis $(n=1904)$ were compared with those of patients who did not $(n=4965)$. The timing of chemoprophylaxis, the rate of VTEs, and the incidence of spinal epidural hematomas were analyzed.

RESULTS The chemoprophylaxis group had more risk factors, including greater age ( 59.70 vs 51.86 years, respectively; $p<0.001$ ), longer surgery (278.59 vs 145.66 minutes, respectively; $p<0.001$ ), higher estimated blood loss (995 vs $448 \mathrm{ml}$, respectively; $p<0.001$ ), more comorbid diagnoses (2.69 vs 1.89 , respectively; $p<0.001)$, history of VTE $(5.8 \%$ vs $2.1 \%$, respectively; $p<0.001)$, and a higher number were undergoing fusion surgery $(46.1 \%$ vs $24.7 \%$, respectively; $p$ $<0.001$ ). The prevalence of VTE was higher in the chemoprophylaxis group ( $3.62 \%$ vs $2.03 \%$, respectively; $p<0.001)$. The median time to VTE occurrence was shorter in the nonchemoprophylaxis group (3.6 vs 6.8 days, respectively; $p=$ 0.0003 , log-rank test; hazard ratio 0.685 [0.505-0.926]), and the peak prevalence of VTE occurred in the first 3 postoperative days in the nonchemoprophylaxis group. The average time of initiation of chemoprophylaxis was 1.46 days after surgery. The rates of epidural hematoma were $0.20 \%(n=4)$ in the chemoprophylaxis group and $0.18 \%(n=9)$ in the nonchemoprophylaxis group ( $p=0.622$ ).

CONCLUSIONS The risks of spinal epidural hematoma among patients who receive chemoprophylaxis and those who do not are low and equivalent. Administering anticoagulation therapy from 1 day before to 3 days after surgery is safe for patients at high risk for VTE.

https://thejns.org/doi/abs/10.3171/2017.3.SPINE161076

KEY WORDS venous thromboembolism; epidural hematoma; chemoprophylaxis; heparin; LMWH; infection

$\mathrm{V}$ ENOus thromboembolisms (VTEs), including deep venous thrombosis (DVT) and pulmonary embolism (PE), are serious complications that cause considerable morbidity and death. ${ }^{13}$ An estimated 2 million people develop DVT in the United States annually, ${ }^{22}$ and approximately 600,000 cases of PE are reported; onethird of PEs lead to death. ${ }^{3}$ After undergoing spine surgery, up to $31 \%$ of patients develop DVT, and up to $7.6 \%$ develop PE. ${ }^{17}$

Although it is known that anticoagulant therapy re-

ABBREVIATIONS BMI = body mass index; DVT = deep venous thrombosis; EBL = estimated blood loss; HR = hazard ratio; ICU = intensive care unit; IVC = inferior vena cava; $\mathrm{PE}=$ pulmonary embolism; RBC = red blood cell; VTE = venous thromboembolism.

SUBMITTED September 26, 2016. ACCEPTED March 14, 2017.

INCLUDE WHEN CITING Published online September 8, 2017; DOI: 10.3171/2017.3.SPINE161076. 
TABLE 1. Types of anticoagulant therapy used for chemoprophylaxis

\begin{tabular}{lcc}
\hline Anticoagulant & Dose & \% of Patients (no.) \\
\hline Heparin & $5000 \mathrm{U}$ & $42.28(805)$ \\
\hline Enoxaparin & $40 \mathrm{mg}$ & $22.64(431)$ \\
\hline Dalteparin & $2500 \mathrm{U}$ & $0.11(2)$ \\
& $5000 \mathrm{U}$ & $34.82(663)$ \\
\hline Fondaparinux & $2.5 \mathrm{mg}$ & $0.16(3)$ \\
\hline
\end{tabular}

duces the number of diagnosed DVTs and PEs in spine surgery patients,,${ }^{10,13,29}$ many spine surgeons believe that the risk of epidural hematoma is increased when anticoagulation therapy is used. The incidence of epidural hematoma has not been well studied, and whether it is associated with anticoagulation has not been robustly demonstrated. ${ }^{17}$ Nevertheless, because epidural hematomas are associated with neurological deficits, many spine surgeons minimize their use of anticoagulants to avoid this complication. . $^{15,16,32}$

To prevent complications from chemoprophylactic anticoagulation, most surgical subspecialties have established guidelines for using it. ${ }^{13,20}$ However, spine surgery lacks robust evidence on the safety, efficacy, and timing of anticoagulation and on the epidemiology of VTE and bleeding complications. ${ }^{15}$ Instead, most published guidelines conclude that more data are needed so that existing guidelines can be improved. ${ }^{5,15-17}$ Moreover, existing guidelines, such as those provided by the National Institute for Health and Care Excellence (NICE), do not specify the timing of VTE chemoprophylaxis but instead advise spine surgeons to exercise clinical judgment when using it. ${ }^{20}$ In the absence of clear guidelines, there is significant variability in the use and timing of VTE prophylaxis after spine surgery. ${ }^{17}$

The goal of this study was to provide further insight into the safety, efficacy, and timing of anticoagulation therapy after spinal surgery. First, we examined the incidence of VTEs among patients who underwent spine surgery and compared data from patients who received chemoprophylaxis to those who did not. Second, we compared the rates of epidural hematoma that required surgical evacuation between the groups (chemoprophylaxis vs nonchemoprophylaxis groups). Third, we examined the timing of VTE formation and the initiation of chemoprophylaxis in these patients.

\section{Methods \\ Data Source}

All patients who underwent spine surgery in the Departments of Neurological Surgery or Orthopedic Surgery of Northwestern University between January 1, 2009, and May 31, 2015, were identified using the Northwestern University Electronic Data Warehouse (EDW). The EDW is a clinical data repository jointly funded by Northwestern Memorial Hospital, the Northwestern Medical Faculty Foundation, and the Northwestern University Feinberg

TABLE 2. Preoperative characteristics of patients

\begin{tabular}{|c|c|c|c|}
\hline Characteristic & Nonchemoprophylaxis Group & Chemoprophylaxis Group & $p$ Value \\
\hline No. of patients & 4965 & 1904 & \\
\hline \multicolumn{4}{|l|}{ Age in yrs } \\
\hline Mean \pm SD & $51.86 \pm 15.45$ & $59.70 \pm 14.41$ & $<0.001$ \\
\hline Median $(95 \% \mathrm{Cl})$ & $52(51.43-52.29)$ & $62(59.05-60.35)$ & $<0.001$ \\
\hline $\operatorname{Sex}(\%[$ no.]) & & & $<0.001$ \\
\hline Male & $56(2774)$ & $47(902)$ & \\
\hline Female & 44 (2191) & $53(1002)$ & \\
\hline \multicolumn{4}{|l|}{ BMl in $\mathrm{kg} / \mathrm{m}^{2}$} \\
\hline Mean \pm SD & $28.11 \pm 5.96$ & $29.31 \pm 6.83$ & $<0.001$ \\
\hline Median $(95 \% \mathrm{Cl})$ & $27.21(27.95-28.28)$ & $27.98(29.00-29.62)$ & $<0.001$ \\
\hline Smoking $\left(\%[\text { no.] })^{*}\right.$ & & & $<0.001$ \\
\hline Never & $84(4159)$ & $85(1621)$ & \\
\hline Current & $15(734)$ & $12(221)$ & \\
\hline Quit <1 yr ago & $1(67)$ & $3(57)$ & \\
\hline VTE history (\% [no.]) & $2.1(104)$ & $5.8(111)$ & $<0.001$ \\
\hline Epidural hematoma history (\% [no.]) & $0.07(1)$ & $0.13(1)$ & 0.4 \\
\hline Bleeding disorder history (\% [no.]) & $2.2(31)$ & $3.6(28)$ & $<0.001$ \\
\hline Neurological deficit (\% [no.]) & $4(60)$ & $6(44)$ & 0.004 \\
\hline \multicolumn{4}{|l|}{ No. of comorbidities } \\
\hline Mean \pm SD & $1.89 \pm 1.48$ & $2.69 \pm 1.35$ & $<0.001$ \\
\hline Median $(95 \% \mathrm{Cl})$ & $2(1.85-1.93)$ & $3(2.63-2.75)$ & $<0.001$ \\
\hline
\end{tabular}

* The numbers and percentages reflect only the data for patients for whom smoking status was known. 
TABLE 3. Procedure characteristics

\begin{tabular}{|c|c|c|c|}
\hline Characteristic & Nonchemoprophylaxis Group & Chemoprophylaxis Group & p Value \\
\hline Timing of anticoagulant in days & NA & 1.46 & \\
\hline IVC filter placed (\% [no.]) & $1.93(96)$ & $8.56(163)$ & $<0.001$ \\
\hline Site of surgery (\% [no.]) & & & $<0.001$ \\
\hline Cervical & $26.5(1313)$ & $24.2(461)$ & \\
\hline Thoracic & $3.7(184)$ & $11.2(213)$ & \\
\hline Lumbar & $69.3(3442)$ & $62.8(1196)$ & \\
\hline Other & $0.5(26)$ & $1.79(34)$ & \\
\hline Fusion (\% [no.]) & $24.7(1225)$ & $46.1(878)$ & $<0.001$ \\
\hline Decompression (\% [no.]) & $33.5(1664)$ & $37.3(710)$ & $<0.001$ \\
\hline Staged surgery (\% [no.]) & $44.30(85)$ & $62.50(100)$ & 0.013 \\
\hline \multicolumn{4}{|l|}{ Surgery time in mins } \\
\hline Mean \pm SD & $145.66 \pm 127.12$ & $278.59 \pm 181.81$ & $<0.001$ \\
\hline Median $(95 \% \mathrm{Cl})$ & $108(142.02-149.10)$ & $228(270.42-286.76)$ & $<0.001$ \\
\hline \multicolumn{4}{|l|}{ Anesthesia time in mins } \\
\hline Mean \pm SD & $205.05 \pm 145.26$ & $363.05 \pm 201.89$ & $<0.001$ \\
\hline Median $(95 \% \mathrm{Cl})$ & $164(200.90-208.98)$ & 309 (353.98-372.13) & $<0.001$ \\
\hline \multicolumn{4}{|l|}{$\mathrm{EBL}$ in $\mathrm{ml}$} \\
\hline Mean \pm SD & $447.98 \pm 1383.62$ & $994.77 \pm 1549.99$ & $<0.001$ \\
\hline Median $(95 \% \mathrm{Cl})$ & 75 (381.45-514.51) & $400(902.48-1087.06)$ & $<0.001$ \\
\hline \multicolumn{4}{|l|}{ Packed RBCs transfused in $\mathrm{ml}$} \\
\hline Mean \pm SD & $1476.04 \pm 1805.34$ & $1315.38 \pm 1262.27$ & 0.004 \\
\hline Median $(95 \% \mathrm{Cl})$ & $800(1256.84-1695.24)$ & 900 (1199.35-1431.42) & 0.721 \\
\hline ICU admission (\% [no.]) & $10.4(518)$ & $39.4(751)$ & $<0.001$ \\
\hline Length of stay in days (median) & 1 & 5 & $<0.001$ \\
\hline $\operatorname{HR}(95 \% \mathrm{Cl})$ & $1.958(2.589-2.849)$ & $0.5107(0.3510-0.3862)$ & \\
\hline
\end{tabular}

$\mathrm{NA}=$ not applicable.

School of Medicine. Spine surgeries were detected using Current Procedural Terminology codes, and all identified primary spine surgeries were included in the analysis. If patients had multiple procedures that required different admissions during this time frame, each operation was analyzed separately. We excluded any patient who underwent reoperation within 30 days, minor spine surgery (including electrode placement or hardware removal), or a secondary procedure (e.g., surgery for wound dehiscence and hematoma evacuation). For each spine surgery included in the study, data about the patient, the procedure, and the postoperative management and recovery were collected. The study was approved by Northwestern University's institutional review board.

\section{Patient Data}

We collected the following patient data: age at surgery, sex, body mass index (BMI), smoking status (never, current, or quit $<1$ year ago), race (Caucasian, African American, Hispanic, Pacific Islander, or other), history of VTEs, history of bleeding disorders, and number of comorbidities (hypertension, cardiac, renal, pulmonary, and endocrine disease) present, as identified by the of International Classification of Diseases, Ninth Revision (ICD-9) codes.

\section{Procedure Data}

We collected the following data about the procedures performed: whether an inferior vena cava (IVC) filter was placed prophylactically, the site of surgery (cervical, thoracic, lumbar, or other), whether a fusion was part of the procedure, whether decompression (laminectomy or laminotomy) was a part of the procedure, whether the surgery was staged across multiple days, the length of surgery (minutes), the length of anesthesia (minutes), estimated blood loss (EBL) (milliliters), transfusion of red blood cells (RBCs) (milliliters), whether the patient was admitted to an intensive care unit (ICU), and the length of hospitalization (days).

\section{Outcome Data}

We also collected data on the use of chemoprophylactic anticoagulation in our patients. Given recent data showing that spine surgeons who use chemoprophylactic anticoagulation do so in the first few days after surgery, ${ }^{15}$ we defined chemoprophylaxis as anticoagulation therapy given between 1 day before and 3 days after surgery. Patients who received anticoagulation outside of this window were assumed to have received it therapeutically. We considered any patient who received $5000 \mathrm{U}$ of heparin, $40 \mathrm{mg}$ of enoxaparin, 2500 or $5000 \mathrm{U}$ of dalteparin, or 2.5 
TABLE 4. Postoperative outcomes within 30 days

\begin{tabular}{|c|c|c|c|}
\hline Outcome & Nonchemoprophylaxis Group & Chemoprophylaxis Group & $p$ Value \\
\hline VTE (\% [no.]) & $2.03(101)$ & $3.62(69)$ & $<0.001$ \\
\hline \multicolumn{4}{|l|}{ Onset in days } \\
\hline Mean \pm SD & $5.83 \pm 6.41$ & $8.52 \pm 6.77$ & 0.672 \\
\hline Median $(95 \% \mathrm{Cl})$ & $3.37(4.56-7.09)$ & $6.79(6.89-10.14)$ & 0.001 \\
\hline PE (\% [no.]) & $0.60(30)$ & $0.79(15)$ & 0.091 \\
\hline \multicolumn{4}{|l|}{ Onset in days } \\
\hline Mean \pm SD & $5.20 \pm 6.30$ & $10.87 \pm 7.85$ & 0.243 \\
\hline Median $(95 \% \mathrm{Cl})$ & $2.86(2.89-7.51)$ & $7.65(6.52-15.22)$ & 0.001 \\
\hline PE w/ IVC filter (\% [no.]) & $8.33(8)$ & $2.45(4)$ & $<0.001$ \\
\hline PE w/o IVC filter (\% [no.]) & $0.45(22)$ & $0.63(11)$ & 0.068 \\
\hline DVT (\% [no.]) & $1.65(82)$ & $3.15(60)$ & $<0.001$ \\
\hline \multicolumn{4}{|l|}{ Onset in days } \\
\hline Mean \pm SD & $6.24 \pm 6.25$ & $8.14 \pm 6.41$ & 0.84 \\
\hline Median $(95 \% \mathrm{Cl})$ & $3.97(4.87-7.61)$ & $6.82(6.49-9.80)$ & 0.041 \\
\hline DVT w/ IVC filter (\% [no.]) & $29.2(28)$ & $14.1(23)$ & $<0.001$ \\
\hline DVT w/o IVC filter (\% [no.]) & $1.11(54)$ & $2.13(37)$ & $<0.001$ \\
\hline Epidural hematoma (\% [no.]) & $0.18(9)$ & $0.21(4)$ & 0.622 \\
\hline \multicolumn{4}{|l|}{ Onset in days } \\
\hline Mean \pm SD & $6.17 \pm 8.59$ & $10.84 \pm 9.44$ & 0.736 \\
\hline Median $(95 \% \mathrm{Cl})$ & $3.19(0.02-12.31)$ & $8.98(-0.88$ to 22.56$)$ & 0.119 \\
\hline Neurological deficit (\% [no.]) & $78(7)$ & $25(1)$ & 0.217 \\
\hline Nonepidural hematoma (\% [no.]) & $0.18(9)$ & $0.26(5)$ & 0.504 \\
\hline \multicolumn{4}{|l|}{ Onset in days } \\
\hline Mean \pm SD & $2.52 \pm 3.68$ & $5.97 \pm 4.80$ & $<0.001$ \\
\hline Median $(95 \% \mathrm{Cl})$ & $6.98(2.41-2.62)$ & $11.88(5.76-6.19)$ & 0.536 \\
\hline Neurological deficit (\% [no.]) & $22(2)$ & $60(3)$ & 0.158 \\
\hline Readmission (\% [no.]) & $3.83(190)$ & $8.19(156)$ & $<0.001$ \\
\hline Reoperation (\% [no.]) & $2.22(110)$ & $3.41(65)$ & $<0.001$ \\
\hline
\end{tabular}

mg of fondaparinux between 1 day before and 3 days after surgery to have received it prophylactically (Table 1). We did not include any patient who received a higher dose of any of these anticoagulants or any patient who received aspirin or warfarin in the chemoprophylaxis group.

Information about complications within 30 days after the surgery included the cumulative 30-day incidence and timing of VTE (defined as either DVT or PE), cumulative 30-day incidence and timing of epidural hematoma, cumulative 30-day incidence of post-epidural hematoma neurological deficit, all-cause readmission, reoperation, and incidence of death.

\section{Statistical Analysis}

Excel 2011 (Microsoft) and Prism 6.0b (GraphPad Software, Inc.) were used to conduct all statistical analyses. Parametric data were recorded as mean \pm SD and compared using the Student t-test, and nonparametric data were compared using the Mann-Whitney U-test or chi-square test, as appropriate. Time-to-event data were analyzed using Mantel-Cox statistics. A p value of $<0.05$ was considered statistically significant.

\section{Results}

\section{Baseline Patient Characteristics}

A total of 6869 procedures met the study inclusion criteria. Compared with the nonchemoprophylaxis group $(\mathrm{n}=$ 4965), patients in the chemoprophylaxis group $(n=1904)$ were older (59.70 vs 51.86 years, respectively; $\mathrm{p}<0.001$ ), had more comorbid diagnoses (2.69 vs 1.89 , respectively; $\mathrm{p}<0.001)$, and were more likely to be female (53\% vs $44 \%$, respectively; $\mathrm{p}<0.001$ ), to have a history of VTE (5.8\% vs $2.1 \%$, respectively; $\mathrm{p}<0.001)$, to have had a history of bleeding disorders in the year before surgery $(3.6 \%$ vs $2.2 \%$, respectively; $\mathrm{p}<0.001$ ), and to have neurological deficits (6\% vs 4\%, respectively; p < 0.001) (Table 2).

Patients in the chemoprophylaxis group had a longer surgery (278.59 vs 145.66 minutes, respectively; $\mathrm{p}<$ $0.001)$, more anesthesia time (363.05 vs 205.05 minutes, respectively; $\mathrm{p}<0.001$ ), and a greater EBL (995 vs $448 \mathrm{ml}$, respectively; $\mathrm{p}<0.001)$ and were more likely to have undergone thoracic surgery $(11.2 \%$ vs $3.71 \%$, respectively; $\mathrm{p}$ $<0.001)$, staged surgery $(62.50 \%$ vs $44.30 \%$, respectively; $\mathrm{p}=0.013)$, and fusion surgery $(46.1 \%$ vs $24.7 \%$, respective- 
TABLE 5. Preoperative characteristics of patients who underwent IVC filter placement

\begin{tabular}{|c|c|c|c|c|}
\hline Characteristic & Nonchemoprophylaxis Group & Chemoprophylaxis Group & Strength of Association $(95 \% \mathrm{Cl})$ & p Value \\
\hline No. of patients & 96 & 163 & & \\
\hline Age in yrs & & & $-3.378(-6.563$ to -0.193$)$ & 0.0377 \\
\hline Mean \pm SD & $59.78 \pm 15.78$ & $63.16 \pm 10.23$ & & \\
\hline Median $(95 \% \mathrm{Cl})$ & $63(56.58-62.98)$ & $64(61.58-64.74)$ & & \\
\hline $\operatorname{Sex}(\%[\mathrm{no}])$. & & & $0.789(0.473-1.318)$ & 0.3650 \\
\hline Male & $44(42)$ & $38(62)$ & & \\
\hline Female & $56(54)$ & $62(101)$ & & \\
\hline $\mathrm{BMl}$ in $\mathrm{kg} / \mathrm{m}^{2}$ & & & $0.451(-1.496$ to 2.397$)$ & 0.6487 \\
\hline Mean \pm SD & $29.89 \pm 7.13$ & $29.44 \pm 7.85$ & & \\
\hline Median $(95 \% \mathrm{Cl})$ & $28.60(28.42-31.36)$ & $27.92(28.22-30.65)$ & & \\
\hline Ever a smoker? (\% [no.]) & $14.58(14)$ & $19.63(32)$ & $1.431(0.720-2.842)$ & 0.3045 \\
\hline Smoking (\% [no.]) & & & & 0.5986 \\
\hline Never & $85.3(81)$ & $80.3(130)$ & & \\
\hline Current & $10.5 \%(10)$ & $14.2(23)$ & & \\
\hline Quit <1 yr ago & $4.2(4)$ & $5.5(9)$ & & \\
\hline VTE history (\% [no.]) & $34.4(33)$ & $25.2(41)$ & $0.642(0.370-1.112)$ & 0.1126 \\
\hline Epidural hematoma history (\% [no.]) & $0(0)$ & $0(0)$ & & \\
\hline Bleeding disorder history (\% [no.]) & $5.17(3)$ & $5.62(5)$ & $1.091(0.251-4.753)$ & 0.9073 \\
\hline Neurological deficit (\% [no.]) & $6.90(4)$ & $4.49(4)$ & $0.635(0.152-2.648)$ & 0.5303 \\
\hline Comorbidities (\% [no.]) & & & & 0.8150 \\
\hline 0 & $0(0)$ & $0(0)$ & & \\
\hline 1 & $5.21(5)$ & $3.07(5)$ & & \\
\hline 2 & $15.63(15)$ & $14.72(24)$ & & \\
\hline 3 & $35.42(34)$ & $33.74(55)$ & & \\
\hline 4 & $31.25(30)$ & $37.42(61)$ & & \\
\hline 5 & $12.50(12)$ & $11.04(18)$ & & \\
\hline Median & 3 & 3 & $0(0.0-0.0)$ & 0.5268 \\
\hline
\end{tabular}

ly; p < 0.001) (Table 3). Patients in the chemoprophylaxis group also were more likely to have been admitted to the ICU (39.4\% vs $10.4 \%$, respectively; $\mathrm{p}<0.001)$.

\section{Rates of VTE}

The rates of VTE were $3.62 \%(n=69)$ in the chemoprophylaxis group and $2.03 \%(\mathrm{n}=101)$ in the nonchemoprophylaxis group $(\mathrm{p}<0.001)$ (Table 4$)$. The rates of DVT were $3.15 \%(n=60)$ in the chemoprophylaxis group and $1.65 \%(\mathrm{n}=82)$ in the nonchemoprophylaxis group $(\mathrm{p}<$ $0.001)$. The rates of PE were $0.79 \%(n=15)$ in the chemoprophylaxis group and $0.60 \%(\mathrm{n}=30)$ in the nonchemoprophylaxis group $(\mathrm{p}=0.091)$.

An IVC filter was placed in $8.56 \%(n=163)$ of the patients in the chemoprophylaxis group and $1.93 \%(\mathrm{n}=96)$ of those in the nonchemoprophylaxis group $(\mathrm{p}<0.001)$ (Table 3). To identify any significant differences in the patients who underwent prophylactic IVC filter placement, we performed a subgroup analysis on their preoperative characteristics (Table 5), procedure characteristics (Table 6), and postoperative outcomes (Table 7). The majority of PEs occurred in patients who underwent placement of an IVC filter (4.63\% [12 of 259]), and the rate was $0.50 \%$ (33 of 6610) for those with no IVC filter, independent of che- moprophylaxis status. Of the patients with an IVC filter, the rates of PE were $2.45 \%$ (4 of 163) in the chemoprophylaxis group and $8.33 \%$ (8 of 96) in the nonchemoprophylaxis group $(p<0.001)$ (Table 7). In the patients without an IVC filter, the rates of PE were $0.63 \%$ (11 of 1741) in the chemoprophylaxis group and $0.45 \%$ (22 of 4869) in the nonchemoprophylaxis group $(\mathrm{p}=0.068)$.

At least a single-level fusion was involved in $30.60 \%$ (n $=2103$ ) of the procedures in our study. Of the procedures in the chemoprophylaxis group, $46.1 \%(\mathrm{n}=878)$ involved fusion, whereas $24.7 \%(\mathrm{n}=1224)$ of the procedures in the nonchemoprophylaxis group involved fusion (Table 3). To identify any significant differences in the patients who underwent fusion, we performed a subgroup analysis on their preoperative characteristics (Table 8), procedure characteristics (Table 9), and postoperative outcomes (Table 10). In this subgroup, we found no significant differences in the rates of VTE events (3.76\% vs $2.61 \%$, respectively), PEs $(1.14 \%$ vs $0.90 \%$, respectively), or DVTs $(2.96 \%$ vs $2.21 \%$, respectively) between the chemoprophylaxis and nonchemoprophylaxis groups $(p>0.05 \%$ ) (Table 10).

Of the patients in the chemoprophylaxis group, 5.83\% $(\mathrm{n}=111)$ had a history of VTE compared with $2.1 \%(\mathrm{n}=$ 104) of patients in the nonchemoprophylaxis group (Table 
TABLE 6. Procedure characteristics of patients who underwent IVC filter placement

\begin{tabular}{|c|c|c|c|c|}
\hline Characteristic & Nonchemoprophylaxis Group & Chemoprophylaxis Group & Strength of Association ( $95 \% \mathrm{Cl}$ ) & $\mathrm{p}$ Value \\
\hline Timing of anticoagulant in days & NA & 1.57 & & \\
\hline IVC filter placed (\% [no.]) & $100(96)$ & $100(163)$ & & \\
\hline Site of surgery (\% [no.]) & & & & 0.2436 \\
\hline Cervical & $13.5(13)$ & $11.7(19)$ & & \\
\hline Thoracic & $31.3(30)$ & $22.7(37)$ & & \\
\hline Lumbar & $55.2(53)$ & $65.0(106)$ & & \\
\hline Other & $0.0(0)$ & $0.6(1)$ & & \\
\hline Fusion (\% [no.]) & $15.6(15)$ & $10.4(17)$ & & \\
\hline Decompression (\% [no.]) & $36.5(35)$ & $20.3(33)$ & $0.442(0.252-0.778)$ & 0.0042 \\
\hline Staged surgery (\% [no.]) & $30.2(29)$ & $35.0(57)$ & $1.431(0.720-2.842)$ & 0.3045 \\
\hline \multicolumn{5}{|l|}{ Surgery time in mins } \\
\hline Mean \pm SD & $473.05 \pm 311.80$ & $547.98 \pm 279.77$ & & \\
\hline Median $(95 \% \mathrm{Cl})$ & $381(409.87-536.23)$ & $545(504.71-591.25)$ & $0.848(0.649-1.088)$ & 0.1931 \\
\hline \multicolumn{5}{|l|}{ Anesthesia time in mins } \\
\hline Mean \pm SD & $575.74 \pm 324.01$ & $657.43 \pm 308.93$ & & \\
\hline Median $(95 \% \mathrm{Cl})$ & $492(510.09-641.39)$ & $623(609.65-705.22)$ & $0.819(0.626-1.053)$ & 0.1178 \\
\hline \multicolumn{5}{|l|}{$\mathrm{EBL}$ in $\mathrm{ml}$} \\
\hline Mean \pm SD & $2326.34 \pm 3748.19$ & $2535.11 \pm 2417.16$ & $-208.8(-1123$ to 705.1$)$ & 0.6527 \\
\hline Median $(95 \% \mathrm{Cl})$ & 1000 (1322.57-3330.11) & 1900 (2110.64-2959.58) & & \\
\hline \multicolumn{5}{|l|}{ Packed RBCs transfused in $\mathrm{ml}$} \\
\hline Mean \pm SD & $2486.06 \pm 2878.98$ & $2123.97 \pm 1509.30$ & $362.1(-335.7$ to 1060$)$ & 0.3069 \\
\hline Median $(95 \% \mathrm{Cl})$ & $1500(1640.76-3331.36)$ & 1850 (1836.06-2411.87) & & \\
\hline Transfusion (\% [no.]) & $48.96(47)$ & $66.26(108)$ & $2.047(1.223-3.428)$ & 0.0061 \\
\hline ICU admission (\% [no.]) & $84.4(81)$ & $89.6(146)$ & $1.590(0.755-3.352)$ & 0.2197 \\
\hline Length of stay in days (median) & 11 & 11 & $1.016(0.792-1.310)$ & 0.8943 \\
\hline
\end{tabular}

2). To identify any significant differences in the patients with a history of VTE, we performed a subgroup analysis on their preoperative characteristics (Table 11), procedure characteristics (Table 12), and postoperative outcomes (Table 13). We found no significant differences in the rates of VTE events (15.32\% vs $25.00 \%)$, PEs (3.60\% vs $9.62 \%)$, or DVTs (13.51\% vs $20.19 \%)$ between the chemoprophylaxis and nonchemoprophylaxis groups ( $\mathrm{p}>0.05)$ (Table 13).

\section{Timing of VTE and Chemoprophylaxis}

The median time to VTE occurrence was shorter in the nonchemoprophylaxis group (3.37 vs 6.79 days, respectively; $p=0.0001)$. The peak prevalence of VTE occurred in the first 3 days after spine surgery in patients who did not receive chemoprophylaxis (Fig. 1). The average time of initiation to chemoprophylaxis was 1.46 days after surgery.

\section{Epidural Hematoma Rates}

The rates of epidural hematoma were $0.21 \%(n=4)$ in the chemoprophylaxis group and $0.18 \%(n=9)$ in the nonchemoprophylaxis group $(\mathrm{p}=0.622)$. The average onset of epidural hematoma was 10.84 days in the chemopro-

TABLE 7. Postoperative outcomes within 30 days for patients who underwent IVC filter placement

\begin{tabular}{|c|c|c|c|c|}
\hline Outcome & Nonchemoprophylaxis Group (\% [no.]) & Chemoprophylaxis Group (\% [no.]) & OR $(95 \% \mathrm{Cl})$ & p Value \\
\hline VTE & $31.3(30)$ & $14.7(24)$ & $0.3989(0.216-0.738)$ & 0.0029 \\
\hline PE & $8.33(8)$ & $2.45(4)$ & $0.277(0.081-0.945)$ & 0.0297 \\
\hline DVT & $29.2(28)$ & $14.11(23)$ & $0.399(0.214-0.744)$ & 0.0033 \\
\hline Epidural hematoma & $0(0)$ & $0.61(1)$ & $1.782(0.072-4.20)$ & 0.4419 \\
\hline Neurological deficit & NA & $100(1)$ & & \\
\hline Nonepidural hematoma & $2.08(2)$ & $1.23(2)$ & $0.584(0.081-4.216)$ & 0.5893 \\
\hline Neurological deficit & $50(1)$ & $50(1)$ & & \\
\hline Readmission & $11.5(11)$ & $12.3(20)$ & $1.081(0.494-2.366)$ & 0.8459 \\
\hline Reoperation & $13.5(13)$ & $4.29(7)$ & $0.287(0.110-0.746)$ & 0.0071 \\
\hline
\end{tabular}


TABLE 8. Preoperative characteristics of patients undergoing fusion

\begin{tabular}{|c|c|c|c|c|}
\hline Characteristic & Nonchemoprophylaxis Group & Chemoprophylaxis Group & Strength of Association $(95 \% \mathrm{Cl})$ & $p$ Value \\
\hline No. of patients & 1224 & 878 & & \\
\hline Age in yrs & & & $-4.484(-5.701$ to -3.267$)$ & $<0.0001$ \\
\hline Mean \pm SD & $53.82 \pm 13.79$ & $58.30 \pm 14.37$ & & \\
\hline Median $(95 \% \mathrm{Cl})$ & $54(53.04-54.59)$ & $60(57.35-59.25)$ & & \\
\hline $\operatorname{Sex}(\%[$ no.]) & & & & 0.1068 \\
\hline Male & $50.5(618)$ & $46.9(412)$ & & \\
\hline Female & $49.5(606)$ & $53.1(466)$ & & \\
\hline BMI in $\mathrm{kg} / \mathrm{m}^{2}$ & & & $-1.016(-1.571$ to -0.461$)$ & 0.0003 \\
\hline Mean \pm SD & $28.05 \pm 6.14$ & $29.06 \pm 6.68$ & & \\
\hline Median $(95 \% \mathrm{Cl})$ & $27.27(27.70-28.39)$ & $27.75(28.62-29.51)$ & & \\
\hline Ever a smoker? (\% [no.]) & & & $0.862(0.680-1.093)$ & 0.2190 \\
\hline Yes & $17.2(210)$ & $15.2(134)$ & & \\
\hline No & $82.8(1013)$ & $84.8(743)$ & & \\
\hline Smoking $\left(\%[\text { no.] })^{*}\right.$ & & & & 0.1325 \\
\hline Never & $82.8(1013)$ & $84.8(743)$ & & \\
\hline Current & $15.8(193)$ & $13.1(115)$ & & \\
\hline Quit <1 yr ago & $1.4(17)$ & $2.1(19)$ & & \\
\hline VTE history (\% [no.]) & $2.45(30)$ & $5.40(21)$ & $2.200(1.377-3.516)$ & 0.0007 \\
\hline Epidural hematoma history (\% [no.]) & $0(0)$ & $0(0)$ & & \\
\hline Bleeding disorder history (\% [no.]) & $1.82(8)$ & $4.88(19)$ & $2.773(1.200-5.409)$ & 0.0131 \\
\hline Neurological deficit (\% [no.]) & $3.64(16)$ & $5.40(21)$ & $1.512(0.777-2.942)$ & 0.2201 \\
\hline Comorbidities (\% [no.]) & & & & $<0.0001$ \\
\hline 0 & $17.40(213)$ & $6.95(61)$ & & \\
\hline 1 & $17.16(210)$ & $13.90(122)$ & & \\
\hline 2 & $19.85(243)$ & $19.70(173)$ & & \\
\hline 3 & $23.69(290)$ & $28.47(250)$ & & \\
\hline 4 & $17.40(213)$ & $23.80(209)$ & & \\
\hline 5 & $4.49(55)$ & $7.18(63)$ & & \\
\hline Median & 2 & 3 & $1(0.0-1.0)$ & $<0.001$ \\
\hline
\end{tabular}

* The numbers and percentages reflect only the data of patients for whom smoking status was known.

phylaxis group and 6.17 days in the nonchemoprophylaxis group ( $\mathrm{p}=0.736$ ) (Fig. 2). Of the patients who developed epidural hematoma, 25\% (1 of 4) in the chemoprophylaxis group and $78 \%$ (7 of 9) in the nonchemoprophylaxis group experienced neurological deficit $(p=0.217)$. A history of epidural hematoma was not associated with receiving chemoprophylaxis $(0.13 \%$ vs $0.07 \% ; \mathrm{p}=0.4)$ (Table 2$)$.

\section{Nonepidural Hematoma Rates}

The rates of nonepidural hematoma were $0.26 \%(\mathrm{n}=$ $5)$ in the chemoprophylaxis group and $0.18 \%(n=9)$ in the nonchemoprophylaxis group $(\mathrm{p}=0.504)$. The average onset of nonepidural hematoma was 5.97 days in the chemoprophylaxis group and 2.52 days in the nonchemoprophylaxis group $(\mathrm{p}<0.001)$. Of the patients who developed nonepidural hematoma, $22 \%$ ( 2 of 9) in the chemoprophylaxis group and 60\% (3 of 5) in the nonchemoprophylaxis group experienced neurological deficit $(\mathrm{p}=0.158)$.

\section{Discussion}

VTEs are common after spine surgery, ${ }^{17}$ and they cause

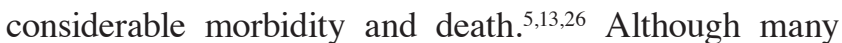
surgical subspecialties have robust guidelines on the use of anticoagulation therapy after surgery ${ }^{11}$ widely accepted guidelines for spine surgery do not exist. ${ }^{6}$ In particular, recommendations do not address the timing of chemoprophylaxis after surgery, and there are insufficient data regarding the epidemiology of VTEs and bleeding complications such as epidural hematoma. ${ }^{15,20}$ In this study, we compared patients who underwent spine surgery at our center and received only mechanical prophylaxis and those who received chemoprophylaxis in addition to mechanical prophylaxis, and we analyzed the 30-day rates for development of VTE, rates of epidural hematoma development, and the timing of VTE development and anticoagulation initiation in each group.

Epidural hematomas were rare in our study, with an overall prevalence of $0.19 \%$. This rate is consistent with those in the existing literature, which shows a 30-day rate of epidural hematoma of less than $1 \%$ in this population. ${ }^{14,16,21}$ In a recent systematic review on epidural hematoma development, Glotzbecker et al. ${ }^{16}$ reported that clinically relevant epidural hematomas occur at a rate of 
TABLE 9. Procedure characteristics of patients undergoing fusions

\begin{tabular}{|c|c|c|c|c|}
\hline Characteristic & Nonchemoprophylaxis Group & Chemoprophylaxis Group & Strength of Association $(95 \% \mathrm{Cl})$ & $\mathrm{p}$ Value \\
\hline Timing of anticoagulant in days & NA & 1.47 & & \\
\hline IVC filter placed (\% [no.]) & $1.23(15)$ & $1.94(17)$ & $1.591(0.790-3.205)$ & 0.1894 \\
\hline Site of surgery (\% [no.]) & & & & $<0.0001$ \\
\hline Cervical & $59.8(732)$ & $26.9(236)$ & & \\
\hline Thoracic & $4.3(52)$ & $10.6(93)$ & & \\
\hline Lumbar & $36.0(440)$ & $62.6(549)$ & & \\
\hline Other & $0(0)$ & $0(0)$ & & \\
\hline Fusion (\% [no.]) & $100(1224)$ & $100(878)$ & & \\
\hline Decompression (\% [no.]) & $18.95(232)$ & $26.77(235)$ & $1.563(1.271-1.922)$ & $<0.0001$ \\
\hline Staged surgery (\% [no.]) & $2.70(33)$ & $2.73(24)$ & $1.014(0.595-1.729)$ & 0.9585 \\
\hline Surgery time in mins & & & $0.6387(0.580-0.688)$ & $<0.0001$ \\
\hline Mean \pm SD & $216.55 \pm 151.69$ & $290.48 \pm 143.94$ & & \\
\hline Median $(95 \% \mathrm{Cl})$ & $174(208.05-225.06)$ & $257(280.95-300.02)$ & & \\
\hline Anesthesia time in mins & & & $0.625(0.567-0.673)$ & $<0.0001$ \\
\hline Mean \pm SD & $283.52 \pm 170.75$ & $369.54 \pm 159.53$ & & \\
\hline Median $(95 \% \mathrm{Cl})$ & $235.50(273.95-293.10)$ & $329.00(358.97-380.11)$ & & \\
\hline $\mathrm{EBL}$ in $\mathrm{ml}$ & & & $55.59(-305.3$ to 416.5$)$ & 0.7624 \\
\hline Mean \pm SD & $1286.58 \pm 2803.07$ & $1230.99 \pm 1735.26$ & & \\
\hline Median $(95 \% \mathrm{Cl})$ & $250(944.26-1628.90)$ & $600(1049.60-1412.37)$ & & \\
\hline Packed RBCs transfused in $\mathrm{ml}$ & & & $531.0(213.1-848.9)$ & 0.0011 \\
\hline Mean \pm SD & $1601.25 \pm 1980.10$ & $1070.24 \pm 1071.44$ & & \\
\hline Median $(95 \% \mathrm{Cl})$ & 957 (1246.34-1956.16) & 750 (932.25-1208.24) & & \\
\hline Transfusion (\% [no.]) & $19.12(234)$ & $13.90(122)$ & $3.282(2.583-4.170)$ & $<0.0001$ \\
\hline ICU admission (\% [no.]) & $19.12(234)$ & $40.43(355)$ & $2.872(2.360-3.494)$ & $<0.0001$ \\
\hline Length of stay in days (median) & 2 & 5 & $0.619(0.487-0.578)$ & $<0.0001$ \\
\hline
\end{tabular}

$0 \%-1 \%$ according to pooled data from the 16 studies that met their inclusion criteria. The rate of this complication among our patients who did not receive chemoprophylaxis $(0.18 \%)$ was equivalent to that among the patients who did receive chemoprophylaxis $(0.20 \%)$. Consistent with our findings, the pooled data from Glotzbecker et al. ${ }^{16}$ revealed no difference between epidural hematoma rates for patients given chemoprophylaxis.

TABLE 10. Postoperative outcomes within 30 days in patients who underwent fusion

\begin{tabular}{|c|c|c|c|c|}
\hline Outcome & Nonchemoprophylaxis Group (\% [no.]) & Chemoprophylaxis Group (\% [no.]) & OR $(95 \% \mathrm{Cl})$ & p Value \\
\hline VTE & $2.61(32)$ & $3.76(33)$ & $1.455(0.887-2.385)$ & 0.1351 \\
\hline VTE w/ IVC filter & $26.67(4)$ & $17.65(3)$ & $0.589(0.108-3.203)$ & 0.5380 \\
\hline VTE w/o IVC filter & $2.32(28)$ & $3.48(30)$ & $1.523(0.903-2.568)$ & 0.1124 \\
\hline PE & $0.90(11)$ & $1.14(10)$ & $1.270(0.537-3.005)$ & 0.5849 \\
\hline PE w/ IVC filter & $6.67(1)$ & $0(0)$ & $0.276(0.010-7.312)$ & 0.2794 \\
\hline PE w/o IVC filter & $0.83(10)$ & $1.16(10)$ & $1.409(0.584-3.401)$ & 0.4434 \\
\hline DVT & $2.21(27)$ & $2.96(26)$ & $1.353(0.784-2.335)$ & 0.2759 \\
\hline DVT w/ IVC filter & $26.67(4)$ & $17.65(3)$ & $0.589(0.108-3.203)$ & 0.5380 \\
\hline DVT w/o IVC filter & $1.90(23)$ & $2.67(23)$ & $1.415(0.789-2.540)$ & 0.2421 \\
\hline Epidural hematoma & $0.08(1)$ & $0.11(1)$ & $1.395(0.087-22.34)$ & 0.8133 \\
\hline Neurological deficit & $100(1)$ & $0(0)$ & & \\
\hline Nonepidural hematoma & $0.25(3)$ & $0.11(1)$ & $0.464(0.048-4.471)$ & 0.4961 \\
\hline Neurological deficit & $33.33(1)$ & $100(1)$ & & \\
\hline Readmission & $3.68(45)$ & $7.18(63)$ & $2.200(1.377-3.516)$ & 0.0007 \\
\hline Reoperation & $2.12(26)$ & $2.39(21)$ & $1.129(0.631-2.020)$ & 0.6823 \\
\hline
\end{tabular}


TABLE 11. Preoperative characteristics of patients with a history of VTE

\begin{tabular}{|c|c|c|c|c|}
\hline Characteristic & Nonchemoprophylaxis Group & Chemoprophylaxis Group & Strength of Association $(95 \% \mathrm{Cl})$ & p Value \\
\hline No. of patients & 104 & 111 & & \\
\hline Age in yrs & & & $-4.497(7.945$ to -1.049$)$ & 0.0108 \\
\hline Mean \pm SD & $58.26 \pm 14.21$ & $62.76 \pm 11.36$ & & \\
\hline Median $(95 \% \mathrm{Cl})$ & $58.50(55.50-61.02)$ & $64.00(60.62-64.89)$ & & \\
\hline Sex (\% [no.]) & & & $1.097(0.642-1.873)$ & 0.7346 \\
\hline Male & $49(51)$ & $51(57)$ & & \\
\hline Female & $51(53)$ & $49(54)$ & & \\
\hline $\mathrm{BMI}$ in $\mathrm{kg} / \mathrm{m}^{2}$ & & & $-0.022(-2.205$ to 2.160$)$ & 0.9838 \\
\hline Mean \pm SD & $30.58 \pm 7.71$ & $30.60 \pm 8.41$ & & \\
\hline Median $(95 \% \mathrm{Cl})$ & $29.05(29.07-32.08)$ & $28.96(29.01-32.19)$ & & \\
\hline Ever a smoker? (\% [no.]) & $13.46(14)$ & $15.32(17)$ & $1.163(0.541-2.497)$ & 0.699 \\
\hline Smoking (\% [no.]) & & & & 0.846 \\
\hline Never & $86.4(89)$ & $84.6(93)$ & & \\
\hline Current & $12.6(13)$ & $13.6(15)$ & & \\
\hline Quit <1 yr ago & $1.0(1)$ & $1.8(2)$ & & \\
\hline VTE history (\% [no.]) & $100(104)$ & $100(111)$ & & \\
\hline Epidural hematoma history (\% [no.]) & $0(0)$ & $0(0)$ & $2.022(0.491-8.334)$ & 0.321 \\
\hline Bleeding disorder history (\% [no.]) & $3.16(3)$ & $6.19(6)$ & $1.098(0.425-2.837)$ & 0.8463 \\
\hline Neurological deficit (\% [no.]) & $9.47(9)$ & $10.31(10)$ & $1.098(0.425-2.837)$ & 0.8463 \\
\hline Comorbidities (\% [no.]) & & & & 0.8408 \\
\hline 0 & $0(0)$ & $0(0)$ & & \\
\hline 1 & $6.73(7)$ & $3.60(4)$ & & \\
\hline 2 & $10.58(11)$ & $13.51(15)$ & & \\
\hline 3 & $29.81(31)$ & $29.73(33)$ & & \\
\hline 4 & $32.69(34)$ & $33.33(37)$ & & \\
\hline 5 & $20.19(21)$ & $19.82(22)$ & & \\
\hline Median & 4.00 & 4.00 & $0(0.0-0.0)$ & 0.9392 \\
\hline
\end{tabular}

The timing of the discovery of epidural hematomas was not significantly different between groups, although the lack of statistical significance might be attributable to the small number of events observed. Important to note is that among patients who experienced epidural hematoma, neurological deficits were more common in the nonchemoprophylaxis group than in the chemoprophylaxis group (78\% vs $25 \%$, respectively).

Our overall rate of VTE was consistent with those in the existing literature, although there was considerable variation among series. Some studies accounted only for clinical presentations of VTE, whereas others also screened for subclinical events, which led to reported VTE rates that varied from $0.3 \%$ to $31 \% .^{8,17}$ In a recent systematic review on VTE after spine surgery, Glotzbecker et al. ${ }^{17}$ calculated an overall VTE rate of $2.1 \%$ when they pooled data from 25 separate studies, which is comparable to the $2.5 \%$ overall rate of VTE we observed in our series.

Our results differ from those of the existing literature by showing that the 30-day rate of VTE among those who received chemoprophylaxis (3.62\%) was higher than the rate among those who did not receive it $(2.03 \%)$. Most studies have found that anticoagulation therapy reduces the incidence of VTE after spine surgery. ${ }^{10,13,20,29}$ This discrepancy is likely attributable to selection factors that surgeons use to determine whether to administer chemoprophylaxis. ${ }^{3,5}$ In our study, patients who received chemoprophylaxis had risk factors known to be associated with a higher incidence of VTE; they were older, had a higher BMI, suffered from more comorbidities, were more likely to have a previous history of VTE, and had a longer operation time. , $^{1,4,6,26,27,31}$

We believe that there would have been a great increase in the number of VTEs had the patients in our chemoprophylaxis group not been given anticoagulation. Moreover, we found no significant difference in the rates of PE in the chemoprophylaxis and nonchemoprophylaxis groups, despite a difference in the rate of DVT, which suggests that anticoagulant therapy might lower the rate of PE in patients who are at a higher risk for it. Because PE is associated with high morbidity and death, decreasing the rate of $\mathrm{PE}$ in this group has the potential to save many lives. ${ }^{20}$

Because the placement of an IVC filter to prevent PE in patients at high risk who undergo spine surgery has become more common, we also compared the incidence of PEs while excluding patients who underwent IVC filter placement to minimize confounding. Again, we found no significant difference in the rates of PE between patients who received chemoprophylaxis and those who did not, which suggests that anticoagulant therapy might lower the rates of $\mathrm{PE}$ in patients at high risk independent of IVC filter 
TABLE 12. Procedure characteristics for patients with a history of VTE

\begin{tabular}{|c|c|c|c|c|}
\hline Characteristic & $\begin{array}{c}\text { Nonchemoprophylaxis } \\
\text { Group }\end{array}$ & $\begin{array}{c}\text { Chemoprophylaxis } \\
\text { Group }\end{array}$ & $\begin{array}{l}\text { Strength of Association } \\
\qquad(95 \% \mathrm{Cl})\end{array}$ & $\begin{array}{c}\mathrm{p} \\
\text { Value }\end{array}$ \\
\hline Timing of anticoagulant in days & NA & 1.45 & & \\
\hline IVC filter placed (\% [no.]) & $31.73(33)$ & $36.94(41)$ & $0.794(0.451-1.396)$ & 0.4220 \\
\hline Site of surgery (\% [no.]) & & & & 0.6640 \\
\hline Cervical & $22(23)$ & $27(30)$ & & \\
\hline Thoracic & $21(22)$ & $22(24)$ & & \\
\hline Lumbar & $57(59)$ & $51(57)$ & & \\
\hline Fusion (\% [no.]) & $28.85(30)$ & $41.44(46)$ & $1.746(0.989-3.081)$ & 0.0535 \\
\hline Decompression (\% [no.]) & $49.04(51)$ & $35.14(39)$ & $0.563(0.326-0.973)$ & 0.0389 \\
\hline Staged surgery (\% [no.]) & $9.62(10)$ & $10.81(12)$ & $1.139(0.470-2.762)$ & 0.7726 \\
\hline Surgery time in mins & & & $0.935(0.714-1.220)$ & 0.618 \\
\hline Mean \pm SD & $284.68 \pm 252.40$ & $301.22 \pm 205.33$ & & \\
\hline Median $(95 \% \mathrm{Cl})$ & $197(235.60-333.77)$ & $247(262.59-339.84)$ & & \\
\hline Anesthesia time in mins & & & $0.882(-336.7$ to 1007$)$ & 0.3252 \\
\hline Mean \pm SD & $363.91 \pm 263.61$ & $398.35 \pm 229.88$ & & \\
\hline Median $(95 \% \mathrm{Cl})$ & $285.20(312.64-415.17)$ & 345.00 (355.11-441.59) & & \\
\hline EBL in $\mathrm{ml}$ & & & $335.3(-336.7$ to 1007$)$ & 0.3252 \\
\hline Mean \pm SD & $1319.17 \pm 2210.35$ & $983.90 \pm 1524.30$ & & \\
\hline Median $(95 \% \mathrm{Cl})$ & $375(677.35-1960.99)$ & $500(628.26-1339.55)$ & & \\
\hline Packed RBCs transfused in $\mathrm{ml}$ & & & $821.0(-142.8$ to 1785$)$ & 0.0936 \\
\hline Mean \pm SD & $2107.51 \pm 2587.80$ & $1286.55 \pm 1000.77$ & & \\
\hline Median $(95 \% \mathrm{Cl})$ & $1425.50(1104.07-3110.96)$ & 1007.50 (937.37-1635.74) & & \\
\hline ICU admission (\% [no.]) & $45.19(47)$ & $58.56(65)$ & $1.714(0.998-2.941)$ & 0.0499 \\
\hline Length of stay in days (median) & 5 & 6 & $1.003(0.767-1.314)$ & 0.9793 \\
\hline
\end{tabular}

placement. One randomized controlled trial demonstrated that prophylactic IVC filter placement increases the rate of DVT among patients with spinal cord injury. ${ }^{18}$ Nevertheless, the rates of $\mathrm{PE}$ were significantly lower in patients who both received chemoprophylaxis and underwent IVC filter placement than in those who only underwent IVC filter placement, which suggests that there could be a role for investigating the safety and efficacy of using IVC filters in combination with chemoprophylaxis in patients at higher risk who undergo spine surgery.

TABLE 13. Postoperative outcomes within 30 days of patients with a history of VTE

\begin{tabular}{|c|c|c|c|c|}
\hline Outcome & Nonchemoprophylaxis Group (\% [no.]) & Chemoprophylaxis Group (\% [no.]) & OR $(95 \% \mathrm{Cl})$ & p Value \\
\hline VTE & $25.00(26)$ & $15.32(17)$ & $0.543(0.275-1.072)$ & 0.0760 \\
\hline VTE w/ IVC filter & $30.30(10)$ & $24.39(10)$ & $0.860(0.302-2.450)$ & 0.7778 \\
\hline VTE w/o IVC filter & $22.54(16)$ & $10.00(7)$ & $0.378(0.126-1.138)$ & 0.0752 \\
\hline PE & $9.62(10)$ & $3.60(4)$ & $0.351(0.107-1.158)$ & 0.0742 \\
\hline PE w/ IVC filter & $12.12(4)$ & $4.88(2)$ & $0.372(0.064-2.171)$ & 0.2565 \\
\hline PE w/o IVC filter & $8.45(6)$ & $2.86(2)$ & $0.3186(0.062-1.637)$ & 0.1511 \\
\hline DVT & $20.19(21)$ & $13.51(15)$ & $0.618(0.299-1.275)$ & 0.1899 \\
\hline DVT w/ IVC filter & $27.27(9)$ & $24.39(10)$ & $0.742(0.265-2.077)$ & 0.5691 \\
\hline DVT w/o IVC filter & $16.90(12)$ & $7.14(5)$ & $0.382(0.146-0.997)$ & 0.0440 \\
\hline Epidural hematoma & $0(0)$ & $0.90(1)$ & $2.837(0.114-70.48)$ & 0.3319 \\
\hline Neurological deficit & NA & $100(1)$ & & \\
\hline Nonepidural hematoma & $0(0)$ & $0.90(1)$ & $2.837(0.114-70.48)$ & 0.3319 \\
\hline Neurological deficit & NA & $100(1)$ & & \\
\hline Readmission & $9.62(10)$ & $18.02(20)$ & $2.066(0.917-4.654)$ & 0.0756 \\
\hline Reoperation & $7.69(8)$ & $2.70(3)$ & $0.333(0.086-1.293)$ & 0.0970 \\
\hline
\end{tabular}




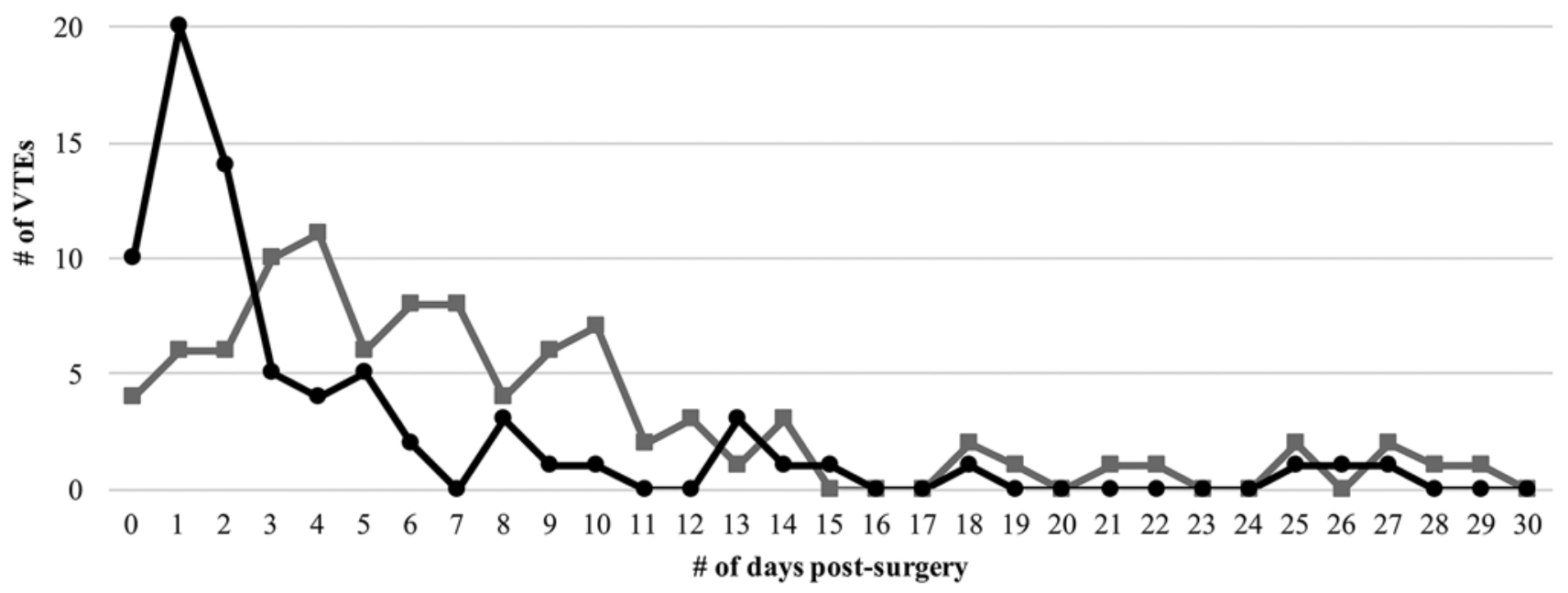

FIG. 1. Timing of VTEs in the chemoprophylaxis $(n=1904)$ and nonchemoprophylaxis $(n=4965)$ groups. The average times to VTE were 8.52 days in the chemoprophylaxis group and 5.83 days in the nonchemoprophylaxis group $(p>0.05)$.

We found a peak prevalence of VTE in the first 3 days after spine surgery in patients who did not receive chemoprophylaxis (Fig. 1). Given that anticoagulation reduces the rate of VTE in patients undergoing spine surgery, ${ }^{10,13,20,29}$ our data suggest that prophylactic anticoagulation therapy is most likely to be effective if given during the first 3 days after surgery. Any anticoagulant therapy initiated at a later time might more likely be therapeutic rather than prophylactic.

The results of our analysis of the timing of VTE development and chemoprophylaxis after elective spine surgery build on the existing literature. Lunzer et al. ${ }^{24}$ showed that for spine patients, postoperative chemoprophylaxis was noninferior to preoperative chemoprophylaxis, although they did not analyze the timing of VTE development and prophylaxis. Kim et al. ${ }^{23}$ showed that VTE prophylaxis

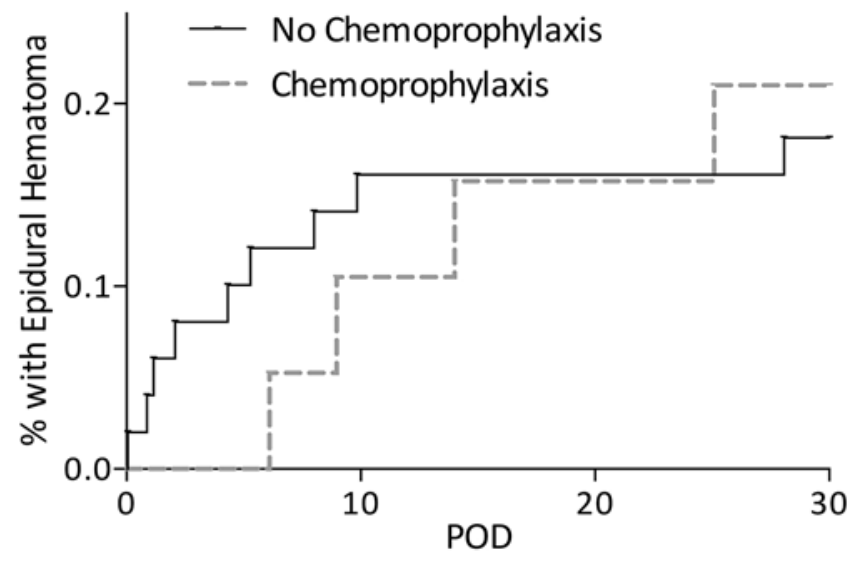

FIG. 2. Cumulative incidence of epidural hematoma after spine surgery in patients who received chemoprophylaxis and in those who did not. No difference between the groups was found ( $p=0.8061$, log-rank test; HR 1.159 [95\% Cl 0.3456-3.922]). POD = probability of detection. is safe within the first 48 hours after surgery, but they analyzed only patients who were undergoing fixation of traumatic spine fracture. Our data better characterize the appropriate timing of VTE development and chemoprophylaxis after spine surgery.

Our analysis differs from those in the existing literature in that we included a larger, broader group of spine surgery patients. Previous studies of patients undergoing spine surgery have examined the incidence of postoperative VTE, $1,4,25,28,30,33$ the effectiveness of chemoprophylaxis for VTE prevention, 2,7,19,24 and complications from anticoagulant therapy. ${ }^{9,12}$ However, these researchers limited their patient populations to specific spinal procedures, such as operative fixation after traumatic spine fracture, ${ }^{23}$ degenerative spinal surgery, ${ }^{33}$ decompression, and fusion procedures. ${ }^{28}$ The narrowed focus of the existing studies limits their external validity and generalizability to other spine patients. Here, we present a broader analysis of patients who were undergoing spine surgery.

Our study has several limitations inherent to its retrospective design. First, we could not determine whether the decision to administer chemoprophylaxis was based on the patients' risk factors, provider preference, or some other cause(s). Second, the use of clinical databases has long been associated with inaccuracies in coding. We found a large number of patients in this study who were coded for a history of malignancy but had no charted evidence of cancer, which led us to exclude the variable altogether. Because the 2 groups in our study were known to be significantly different with respect to several other VTE risk factors, we do not believe it would have had a further effect on our conclusions. In addition, the use of clinical databases also limited us to the amount and type of information we were able to collect. For example, we were unable to evaluate the use of postoperative drains because of the variability in the location of this information, including daily progress notes that cannot be coded reliably, as evi- 
denced by the inaccurate charting of malignancy histories. Third, detection bias might have increased the number of VTE events detected in the chemoprophylaxis group, because the baseline clinical characteristics that placed them at high risk might have prompted more vigilance from their providers. Indeed, patients in the chemoprophylaxis group were more likely to be admitted to the ICU than patients in the nonchemoprophylaxis group $(39.4 \%$ vs $10.4 \%$, respectively; $\mathrm{p}<0.001)$. Finally, patients who suffered a complication might have sought assistance at a different institution, which would have caused ascertainment bias and underestimation of the true rates of VTE and epidural hematoma.

Despite these limitations, to our knowledge, our study is the only investigation in the spine surgery literature designed specifically to address the timing of initiation of VTE chemoprophylaxis after primary spine procedures.

\section{Conclusions}

VTE complications after spine surgery typically occur during the first 3 postoperative days. Chemoprophylactic anticoagulation can be used without an increase in the risk of epidural hematoma, even when it is initiated within the first 48 hours after surgery.

\section{References}

1. Akeda K, Matsunaga H, Imanishi T, Hasegawa M, Sakakibara T, Kasai Y, et al: Prevalence and countermeasures for venous thromboembolic diseases associated with spinal surgery: a follow-up study of an institutional protocol in 209 patients. Spine (Phila Pa 1976) 39:791-797, 2014

2. Al-Dujaili TM, Majer CN, Madhoun TE, Kassis SZ, Saleh AA: Deep venous thrombosis in spine surgery patients: incidence and hematoma formation. Int Surg 97:150-154, 2012

3. Bell WR, Simon TL: Current status of pulmonary thromboembolic disease: pathophysiology, diagnosis, prevention, and treatment. Am Heart J 103:239-262, 1982

4. Born TR, Engasser WM, King AH, Krych AJ, Dahm DL, Levy BA, et al: Low frequency of symptomatic venous thromboembolism after multiligamentous knee reconstruction with thromboprophylaxis. Clin Orthop Relat Res 472:2705-2711, 2014

5. Bryson DJ, Uzoigwe CE, Braybrooke J: Thromboprophylaxis in spinal surgery: a survey. J Orthop Surg 7:14, 2012

6. Clagett GP, Anderson FA Jr, Geerts W, Heit JA, Knudson M, Lieberman JR, et al: Prevention of venous thromboembolism. Chest 114 (5 Suppl):531S-560S, 1998

7. Cox JB, Weaver KJ, Neal DW, Jacob RP, Hoh DJ: Decreased incidence of venous thromboembolism after spine surgery with early multimodal prophylaxis: clinical article. J Neurosurg Spine 21:677-684, 2014

8. Cunningham JE, Swamy G, Thomas KC: Does preoperative DVT chemoprophylaxis in spinal surgery affect the incidence of thromboembolic complications and spinal epidural hematomas? J Spinal Disord Tech 24:E31-E34, 2011

9. Du W, Zhao C, Wang J, Liu J, Shen B, Zheng Y: Comparison of rivaroxaban and parnaparin for preventing venous thromboembolism after lumbar spine surgery. J Orthop Surg 10:78, 2015

10. Epstein NE: A review of the risks and benefits of differing prophylaxis regimens for the treatment of deep venous thrombosis and pulmonary embolism in neurosurgery. Surg Neurol 64:295-302, 2005

11. Falck-Ytter Y, Francis CW, Johanson NA, Curley C, Dahl
OE, Schulman S, et al: Prevention of VTE in orthopedic surgery patients: Antithrombotic Therapy and Prevention of Thrombosis, 9th ed: American College of Chest Physicians Evidence-Based Clinical Practice Guidelines. Chest 141 (2 Suppl):e278S-e325S, 2012

12. Fang MC, Maselli J, Lurie JD, Lindenauer PK, Pekow PS, Auerbach AD: Use and outcomes of venous thromboembolism prophylaxis after spinal fusion surgery. J Thromb Haemost 9:1318-1325, 2011

13. Geerts WH, Bergqvist D, Pineo GF, Heit JA, Samama CM, Lassen MR, et al: Prevention of venous thromboembolism: American College of Chest Physicians Evidence-Based Clinical Practice Guidelines (8th Edition). Chest 133 (6 Suppl):381S-453S, 2008

14. Gerlach R, Raabe A, Beck J, Woszczyk A, Seifert V: Postoperative nadroparin administration for prophylaxis of thromboembolic events is not associated with an increased risk of hemorrhage after spinal surgery. Eur Spine J 13:9-13, 2004

15. Glotzbecker MP, Bono CM, Harris MB, Brick G, Heary RF, Wood KB: Surgeon practices regarding postoperative thromboembolic prophylaxis after high-risk spinal surgery. Spine (Phila Pa 1976) 33:2915-2921, 2008

16. Glotzbecker MP, Bono CM, Wood KB, Harris MB: Postoperative spinal epidural hematoma: a systematic review. Spine (Phila Pa 1976) 35:E413-E420, 2010

17. Glotzbecker MP, Bono CM, Wood KB, Harris MB: Thromboembolic disease in spinal surgery: a systematic review. Spine (Phila Pa 1976) 34:291-303, 2009

18. Gorman PH, Qadri SF, Rao-Patel A: Prophylactic inferior vena cava (IVC) filter placement may increase the relative risk of deep venous thrombosis after acute spinal cord injury. J Trauma 66:707-712, 2009

19. Hamidi S, Riazi M: Incidence of venous thromboembolic complications in instrumental spinal surgeries with preoperative chemoprophylaxis. J Korean Neurosurg Soc 57:114118,2015

20. Hill J, Treasure T: Reducing the risk of venous thromboembolism (deep vein thrombosis and pulmonary embolism) in patients admitted to hospital: summary of the NICE guideline. Heart 96:879-882, 2010

21. Jacobs LJ, Woods BI, Chen AF, Lunardini DJ, Hohl JB, Lee JY: Safety of thromboembolic chemoprophylaxis in spinal trauma patients requiring surgical stabilization. Spine (Phila Pa 1976) 38:E1041-E1047, 2013

22. Jaffer AK: An overview of venous thromboembolism: impact, risks, and issues in prophylaxis. Cleve Clin J Med 75 (Suppl 3):S3-S6, 2008

23. Kim DY, Kobayashi L, Chang D, Fortlage D, Coimbra R: Early pharmacological venous thromboembolism prophylaxis is safe after operative fixation of traumatic spine fractures. Spine (Phila Pa 1976) 40:299-304, 2015

24. Lunzer A, Vavken P, Grohs JG: A prospective, active-control, non-inferiority study of the effectiveness of low molecular weight heparin in the prophylaxis of postoperative thrombotic events in patients undergoing spinal surgery. Orthop Muscular Syst 4:185, 2015

25. McClendon J Jr, Smith TR, O'Shaughnessy BA, Sugrue PA, Thompson SE, Koski TR: Time to event analysis for the development of venous thromboembolism after spinal fusion $\geq$ 5 levels. World Neurosurg 84:826-833, 2015

26. Oda T, Fuji T, Kato Y, Fujita S, Kanemitsu N: Deep venous thrombosis after posterior spinal surgery. Spine (Phila Pa 1976) 25:2962-2967, 2000

27. Sansone JM, del Rio AM, Anderson PA: The prevalence of and specific risk factors for venous thromboembolic disease following elective spine surgery. J Bone Joint Surg Am 92:304-313, 2010

28. Schairer WW, Pedtke AC, Hu SS: Venous thromboembolism after spine surgery. Spine (Phila Pa 1976) 39:911-918, 2014 
29. Schizas C, Neumayer F, Kosmopoulos V: Incidence and management of pulmonary embolism following spinal surgery occurring while under chemical thromboprophylaxis. Eur Spine J 17:970-974, 2008

30. Schulte LM, O'Brien JR, Bean MC, Pierce TP, Yu WD, Meals C: Deep vein thrombosis and pulmonary embolism after spine surgery: incidence and patient risk factors. Am J Orthop 42:267-270, 2013

31. Tominaga H, Setoguchi T, Tanabe F, Kawamura I, Tsuneyoshi Y, Kawabata N, et al: Risk factors for venous thromboembolism after spine surgery. Medicine (Baltimore) 94:e466, 2015

32. Yi S, Yoon DH, Kim KN, Kim SH, Shin HC: Postoperative spinal epidural hematoma: risk factor and clinical outcome. Yonsei Med J 47:326-332, 2006

33. Yoshioka K, Murakami H, Demura S, Kato S, Tsuchiya H: Prevalence and risk factors for development of venous thromboembolism after degenerative spinal surgery. Spine (Phila Pa 1976) 40:E301-E306, 2015

\section{Disclosures}

Dr. Koski has direct stock ownership in NuVasive and has been a consultant for NuVasive, Medtronic, and Spine Wave.

\section{Author Contributions}

Conception and design: Dahdaleh, Dhillon, Khanna. Acquisition of data: Dhillon, Khanna, Roberts. Analysis and interpretation of data: Dahdaleh, Dhillon, Khanna, Cloney. Drafting the article: Dhillon, Cloney. Critically revising the article: Dahdaleh, Dhillon, Khanna, Cloney, Cybulski, Koski, Smith. Reviewed submitted version of manuscript: all authors. Approved the final version of the manuscript on behalf of all authors: Dahdaleh. Statistical analysis: Dhillon, Khanna, Cloney. Administrative/technical/ material support: Dahdaleh. Study supervision: Dahdaleh, Cybulski, Koski, Smith.

\section{Supplemental Information}

\section{Previous Presentations}

Portions of this work were presented as a Kuntz Scholar orally at the 33rd Annual Meeting of the Section on Disorders of the Spine and Peripheral Nerves, Congress of Neurological Surgeons, Orlando, Florida, March 17, 2016.

\section{Correspondence}

Nader S. Dahdaleh, Department of Neurological Surgery, Northwestern University, Feinberg School of Medicine, 676 N Saint Clair St., Ste. 2210, Chicago, IL 60611. email: nader.dahdaleh@ northwestern.edu. 